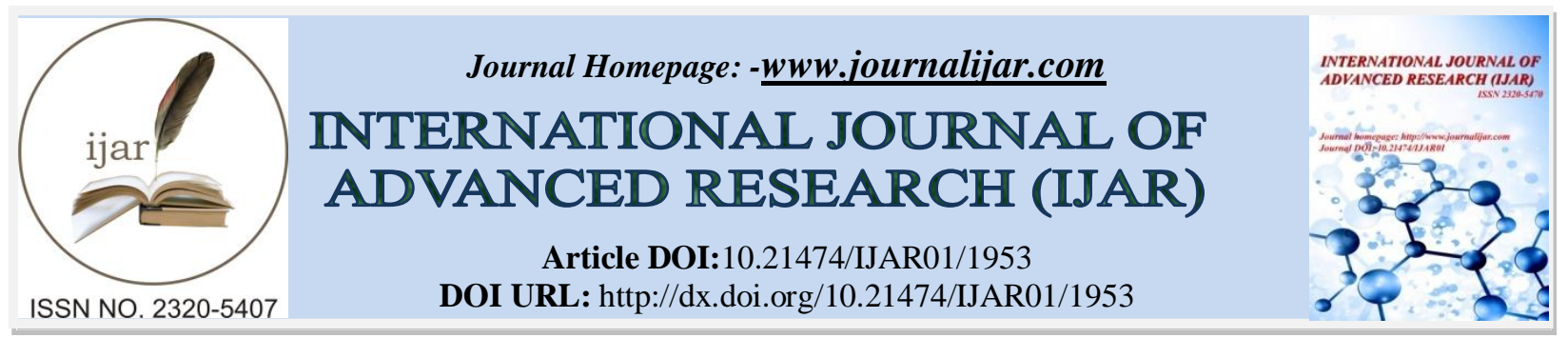

RESEARCH ARTICLE

\title{
THE BENEFICIAL EFFECT OF THIAMINE IN CISTUS SALVIIFOLIUS NEUROTOXICITY CONTROL
} IN SHEEP.

\section{Lahkak Fatima Ezzahra ${ }^{1}$, Bencheikh Fatima Zahra ${ }^{1}$, Bamouh Zahra ${ }^{1}$, Kajei Asmae ${ }^{1}$, Akba Mohammed Amine $^{1}$, Alali Said ${ }^{2}$, Bassou Driss ${ }^{3}$, El Hamidi Mohamed ${ }^{4}$ and Oukessou Mohamed ${ }^{1 *}$.}

1. Department of Biological and Pharmaceutical Sciences, Hassan II Agronomic and Veterinary Institute, POB 6202, 1010, Rabat, Morocco.

2. Department of Medicine, Surgery and Reproduction, Hassan II Agronomic and Veterinary Institute, POB 6202, 1010, Rabat, Morocco.

3. Centre de Radiologie des Hopitaux, Rabat, Morocco.

4. Department of Pathology and Veterinary Public Health, Hassan II Agronomic and Veterinary Institute, POB 6202, 1010, Rabat, Morocco.

\section{Manuscript Info}

(..........................

Manuscript History

Received: 22 August 2016

Final Accepted: 12 September 2016

Published: October 2016

Key words:-

Cistussalviifolius poisoning,

Sulbutiamine, Thiamine deficiency,

Sheep, Morocco.

\section{Abstract}

Moroccan sheep is permanently exposed to an abundance of endemic toxic plants among which peculiarly Cistussalviifolius (also known as rockrose). The ingestion in excess of this plant by sheep is usually associated with nervous signs including episodic convulsions, opisthotonos, nystagmus, and paddling movements. To our best knowledge, no specific treatment of thisshrub poisoning is not yet described. Thus, the objective of the present study was to investigate the effect of sulbutiamine, a thiamine derivative known for its beneficial actions in numerous neurological disorders, in rockrose neurotoxicity. For this purpose, 53 affected adult sheep including 50 ewes and 3 rams were subjected to sulbutiamine treatment. Furthermore, in the attempt to highlight a possible thiamine deficiency involvement in the studied disorder, additional tests were performed on 10 other affected animals and rockrose samples.

The use of sulbutiamineat a dosage rate of approximately 30 to 60 $\mathrm{mg} / \mathrm{kg} \mathrm{BW}$ orally during 4 to 7 consecutive days or 5 to $15 \mathrm{mg} / \mathrm{kg} \mathrm{BW}$ as single IM injections allowed clinical recovery of $82 \%$ and $100 \%$ of treated animals respectively.

MRI and histological examination, performed on three non-treated animals,revealed in one sheep a unilaterally hyperintensity and a granular-vacuolar degeneration of certain neurons in the regionof the pons respectively.

Levels ofcondensed tannins, sulfites and sulfates in C.salviifolius were the highest during the autumn, from November to January and during February and March respectively.

The present investigation has elucidated the beneficial effect of sulbutiamine in C.salviifolius poisoning in sheep and suggests a thiamine deficiency involvement in the observed symptoms. 


\section{Introduction:-}

Sheep production in Morocco is largely dominated by extensive system livestock where feeding resources are mainly forests, stubbles and fallows. In the particular case of middle Atlas mountains, characterized by the pastoral system, sheep are maintained on forest during autumn, winter and a part of spring. Combined with the pasture scarcity during these seasons in these areas, such a practice constantly exposes livestock to plant poisoning. The plants poisoning to sheep may be secondary to the consumption of plants either naturally toxic or in excess of those ordinary considered as pastoral. The latter case applies perfectly to the C. salviifoliusshrub, which represents the main flora of the undergrowth of forests in areas of low mountains and considered safe to livestock. However, when consumed in excess by sheep or cattle, this plant leads to drastic poisoning phenomenon. C. salviifoliuspoisoning in cattle is manifested by a nephro-urinary syndrome dominated by a severe cystitis and pyelonephritis (Yerham et al., 2002); whereas, neurological disorders are described in sheep (Soler Rodriguez et al., 1995; San Andrés et al., 2000; Soler Rodríguez, 2000; Lahkak et al., 2014). The main symptoms of $C$. salviifolius poisoning in sheep are episodes of convulsion with pedaling movements, opisthotonosis and nystagmus (Soler Rodriguez et al., 1995; San Andrés et al., 2000; Soler Rodríguez, 2000; Lahkak et al., 2014). The convulsive crises are mainly triggered by external stimuli such as excitation or during the exit from enclosures (Lahkak et al., 2014). To our best knowledge, the underlying mechanisms of nervous disorders resulting from $C$. salviifolius poisoning are not previously described and, consequently, no specific treatments are available. Therefore, taking into account the great similarity between the symptoms related $C$. salviifolius poisoning and those induced by thiamine deficiency, we hypothesized that the use of thiamine derivatives could be beneficial in case of poisoning with this shrub. To confirm or disprove our hypothesis, we had undertaken the following two studies (i) Clinical, biochemical and therapeutic follow-up of affected animals (ii) chemical analysis of $C$. salviifolius.

\section{Materials and Methods:-}

\subsection{Animals:-}

The study was conducted in the AitIchou area in the middle Atlas mountains of Morocco from November 2012 to December 2015 and concerned 53 affected sheep including 50 ewes and 3 rams. Forty-three (43) animals were kept in their respective flocks and ten untreated ewes were transferred to the laboratory among which 3 animals were, soon after their reception, allocated to MRI and histological tests whereas le remaining 7 were followed-up under controlled conditions. All animals were adults and the females were in various reproductive states. The criterion of inclusion of animals in this study was either occurrence of seizures spontaneously or following excitation in our presence. This inclusion was often supported by the presence of trauma and defilement of the fleece consecutive to falls. It is worth noting that the convulsive crisis frequency is difficult to determine precisely because of the extensive sheep management.

\subsection{Clinical examination:-}

Animals under controlled conditions were subjected to clinical and neurological examinations. Neurological examination consisted of the examination of the skull and spine, behavior in response to external stimuli, exploring the superficial tactile or painful sensitivity, defensive reflexes and control of the upright attitude.

The animals were subjected to excitations by sudden frightening.

The intensity of the crisis was evaluated by their frequency, duration and severity. Seizures severitywas subjectively judged by the degree of knocking the head against the floor, pedaling movements and intensity of opisthotonosis.

\subsection{Blood analysis:-}

Blood samples $(5 \mathrm{ml})$ were collected from the jugular vein into heparinized tubes, prior to treatment, from seven animals under controlled conditions and six others from the field. Blood samples were used for packed cell volume (hematocrit) measurement and biochemical analysis (blood urea nitrogen (BUN), creatinine, glucose, calcium, phosphate, magnesium and gamma-glutamyltransferase (GGT)). Biochemical and hematological tests were carried out using conventional techniques.

\subsection{Magnetic Resonance Imaging (MRI) of the brain:-}

After being humanely euthanized, three affected and untreated ewes among those under observation were decapitated and heads were immediately put in a portable cooler and forwarded to a radiology center where MRI was performed.MRI images were obtained using a 1.5T machine (Optima, GE Medical Systems, Milwaukee, Wis). The imaging protocol includes a T2 sequence (TR/TE/NEX 2575/103/2) and Flair sequence (TR/TI/TE/NEX 9000/2250/140/1) in the transverse axial plane with a thickness of $4 \mathrm{~mm}$.Target areas were the cerebral cortex, cerebellum and the annular protrusions (pons). 


\subsection{Histological Evaluation:-}

Brains were quickly recovered from two heads subjected to MRI and tissue samples were performed at predetermined sites including those that showed abnormalities on MRI. Sections of brain tissue samples were fixed in $10 \%$ buffered neutral formalin and processed by routine histological methods. Multiple 4-6 $\mu \mathrm{m}$ thick sections were stained with Hematoxylin-Eosin-Saffron (HES).

\subsection{Plants analysis:-}

A total of 24 samples of $C$. salviifolius, collected between November 2013 and April 2014, were analyzed. The samples were taken from 10 different sites in the study area, particularly from pastures frequented by flocks where sheep with nervous disorder were observed. Of the 24 plant samples analyzed, sixteen were in pre-flowering and eight in post-flowering stages (Fig. 1A-D).

Samples, especially leaves and flowers, were identified and transported within 4 to 5 hours to the laboratory for dry matter (DM) determination, sulfur and condensed tannins (CT) quantification and acidifying power measurements.

DM was determined by weighing a test sample before and after drying at $105^{\circ} \mathrm{C}$ for $24 \mathrm{~h}$. The acidifying power was estimated by measuring the $\mathrm{pH}$ changes of an aqueous homogenate of dried plant. Briefly, after drying at laboratory temperature, the plant was finely ground and $1.0 \mathrm{~g}$ of the powder was homogenized in $50 \mathrm{ml}$ of distilled water at $\mathrm{pH}$ 7.4. The mixture was kept under gentle stirring at room temperature, and the $\mathrm{pH}$ measurement was performed 10 min after the plant addition.

Sulfites in plant samples were estimated by the method AFNOR (French Agency for Standardization) NFT 90023. The principle of the technique is based on the oxidation of sulfites in the presence of iodine and acids, then, the iodine excess is titrated with thiosulfate. Sulfates were determined by the method described by Rodier (1996).

Quantification of CT (proanthocyanidins) was carried out using a colorimetric technique described by Poter et al., (1986). This technique is based on the oxidative depolymerization of proanthocyanidins to form red anthocyanins which are quantified at $550 \mathrm{~nm}$.
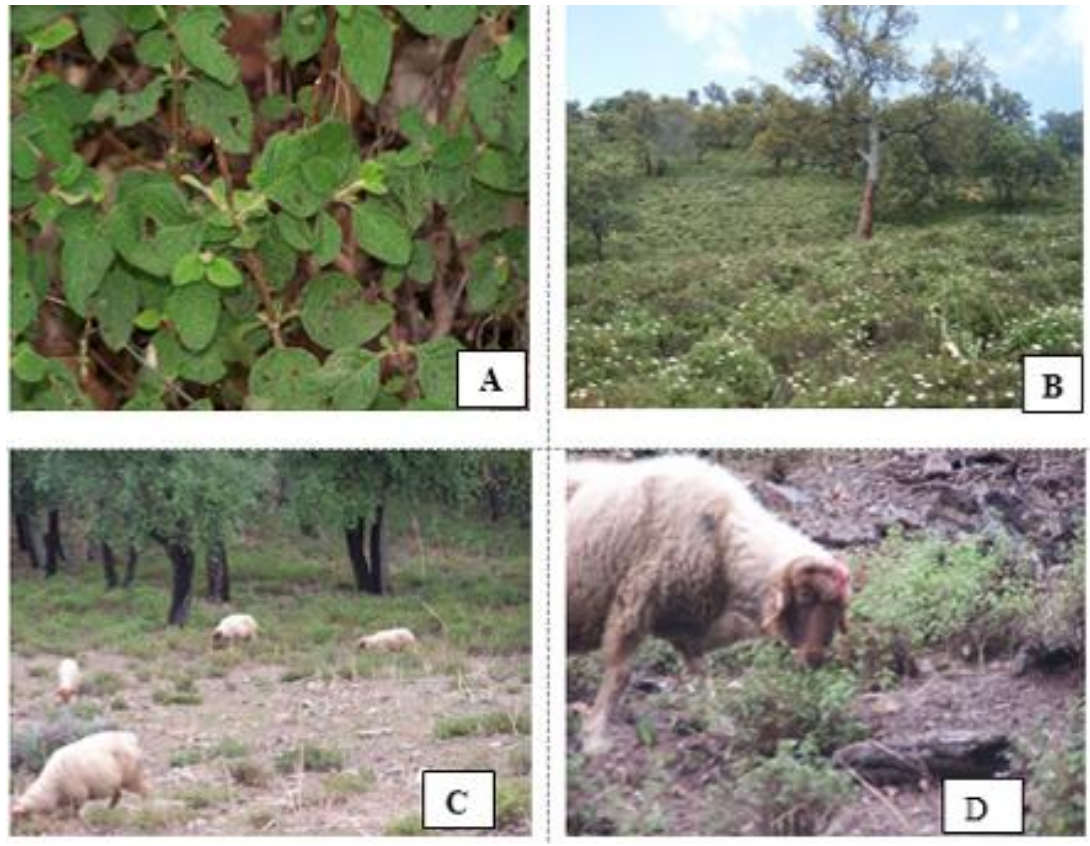

Fig. 1 : A-B : Pictures of the plant $C$. salviifolius in pre-flowering (A) and post-flowering (B) stages. C-D : Pictures showing sheep on a pasture invaded by of $C$. salviifoliusshrubs.

\subsection{Therapeutic trials:-}

Two sulbutiamine preparations were used in this study. A $10 \%$ suspension obtained by suspending sulbutiamine powder (purity $>98 \%$ ) in distilled water containing $0.5 \%$ of xanthan gum and a $10 \%$ injectable solution prepared in 
dimethylsulfoxide and N-methyl-2-pyrrolidone. Both $10 \%$ preparations were stable for at least two months. A total of 39 affected sheep were treated orally at total dose of 1.0 to $2.0 \mathrm{~g} / \mathrm{animal} / \mathrm{day}$, depending on animal body weights (BW) and severity of seizures, for 4 to 7 consecutive days. Delayed recovery (> 7 days) and recurrent cases after oral treatment have received intramuscularly a single injection of the $10 \%$ solution at a total dose of $500.0 \mathrm{mg}$. Four ewes have received from the outset a single intramuscular sulbutiamine injection at a total dose of 200 to $500 \mathrm{mg}$ depending animal body weight and seizures severity. Based on visual body weight estimation, the used sulbutiamine dosages deliver approximately 30 to $60 \mathrm{mg} / \mathrm{kg}$ BW orally and 5 to $15 \mathrm{mg} / \mathrm{kg} \mathrm{BW}$ for injectable solution (for therapeutic protocol see Table 2). Treatments were started by our team and, in repeated dosing cases, relayed by the owners with instructions to follow the product protocol and inform us about affected animal outcome. For oral administration, treatment should be continued for 2 to 3 days after seizures cessation without exceeding, however, seven consecutive days. The clinical status of each affected animal was monitored by regular veterinary visits and/or by local owners who made available their daily observations by telephone.

\section{Results:-}

\subsection{Clinical examination:-}

During the period of adaptation, five sheep among those under observation exhibited epileptiform crises following external stimuli. While the other two sheep showed no seizures.

The crises were characterized by falling down, pedaling movements, nystagmus and opisthotonos (Fig. 2A-C). At the end of the crisis, the animal got-up and returned to normal habitus. Often, the animal urinated immediately after crisis.

With the exception of few injuries and defilement of the fleece due to falling down, affected animals showed no other clinical abnormalities which may be related to the nervous disorder.

The only consistent symptom observed in affected animals was seizures, occurring either spontaneously or triggered by an external stimuli, which usually lasted 5 seconds to 10 minutes.
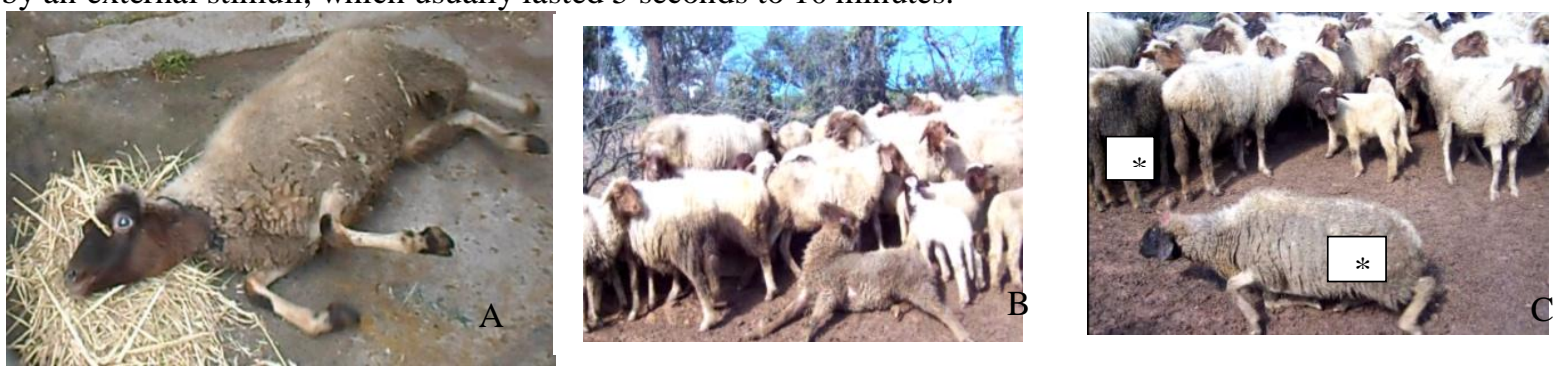

Fig. 2 :A. A sheep under controlled conditions during a severe convulsive crisis exhibiting pedaling movements, nystagmus and opisthotonos. B \& $\mathbf{C}$. Two ewes in the field showing convulsive seizures after excitation (*indicates the same sheep during and after the crisis).

\subsection{Blood and biochemical analysis:-}

Blood and biochemical parameters showed that the obtained values from affected animals were similar to usual values reported from unaffected sheep (data no presented).

\subsection{Magnetic Resonance Imaging:-}

The MRI performed on three brains revealed a unilaterally hyperintensity in the regionof the pons in one sheep (Fig. 3). Except for this, no anomaly signal of brain parenchyma was detected. The furrows, cisterns and ventricles were in normal size. 

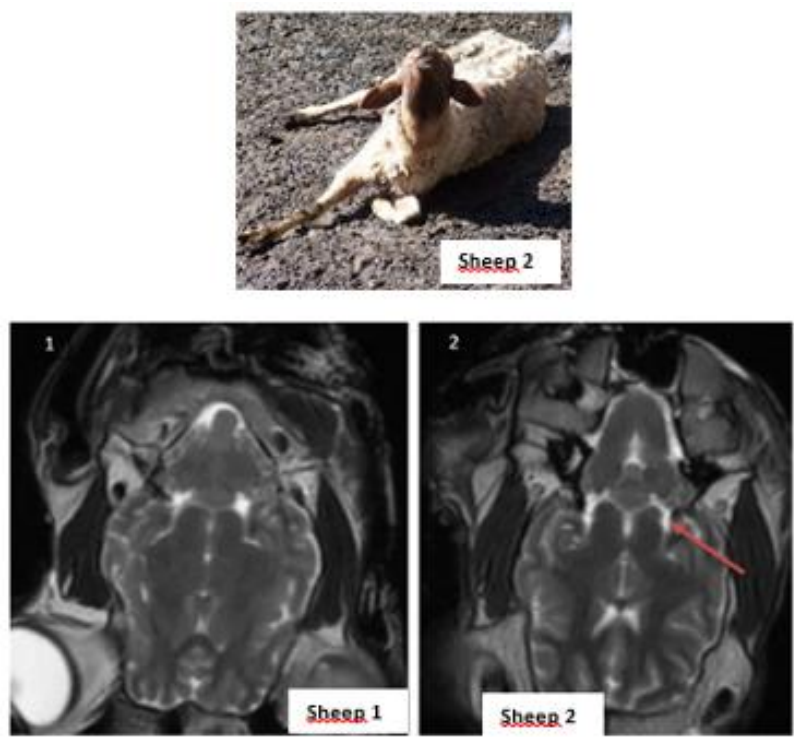

Fig. 3: MRI showing ( ) a unilaterally hyperintensity in the regionof the pons in sheep 2. (Sheep 2, with opisthotonos, is shown in the boxabove). Result for sheep 1 in given for comparison. The sheep 1 was clinically affected but with negative MRI and histology.

\subsection{Histological study:-}

The histopathology detects a granular-vacuolar degeneration of certain neurons in the same area for the same sheep that had showed MRI abnormality (Fig. 4).

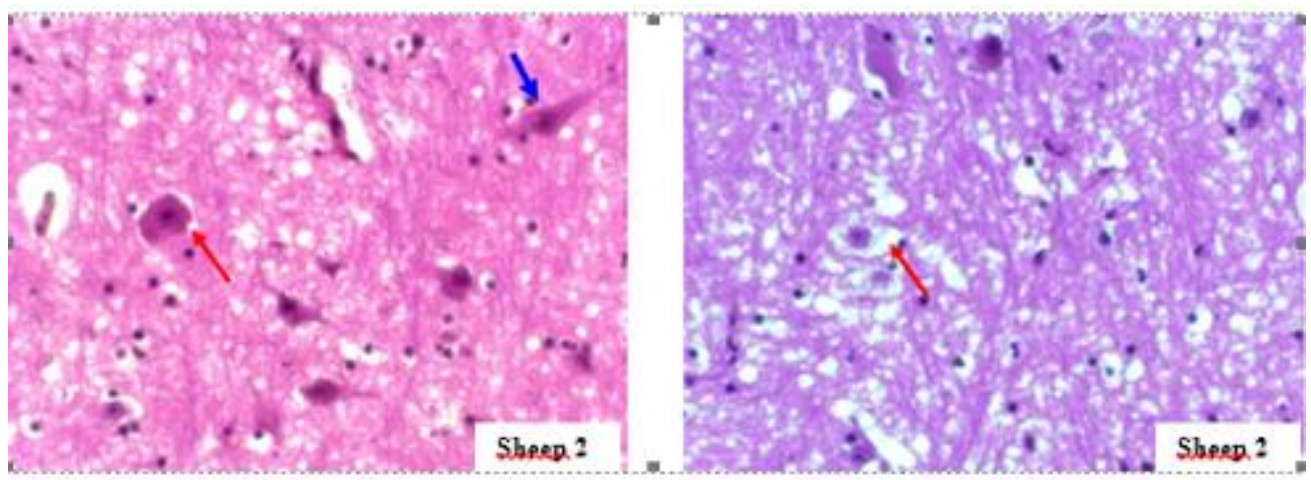

Fig. 4 : Histological aspect in sheep 2 showing $(*)$ a granular-vacuolar degeneration of certain neurons in the same area as MRI imaging. ( $\downarrow$ indicates a normal neuron).

\section{Plant Analysis:-}

The results obtained for DM, sulfites, sulfates, CT and acidification power were summarized in Table 1. DM content in C. salviifolius was the highest in February to April and the lowest during November. Whereas, CT content have shown large variations within period and between periods as well as. Such variations could be attributed to the degree of sun exposition (shady or sunny areas) and the soil type where plants were sampled. These parameters were not considered in our study. However, the level of CT decreased on average progressively from November (31.6\% DM) to April (0.48\% DM).

The sulfate levels were on average higher in samples collected during February and March and the sulfites were higher in those collected during November to January than during the other periods.

Extracts of all C. salviifoliussamples have a relatively high acidifying power insofar as they resulted in $\mathrm{pH}$ decrease from 7.4 to approximately 5.0 within $10 \mathrm{~min}$. 
Table 1 :Cistussalviifolius composition (mean and range) variation from November to April.

\begin{tabular}{|c|c|c|c|c|c|}
\hline Period & pH & $\begin{array}{l}\text { Dry matter } \\
(\mathrm{DM})(\%)\end{array}$ & $\begin{array}{l}\text { Condensed tannins } \\
(\% \mathrm{DM})\end{array}$ & $\begin{array}{l}\text { Sulfates } \quad(\mathrm{mg} / \mathrm{kg} \\
\text { DM })\end{array}$ & $\begin{array}{l}\text { Sulfites } \quad(\mathrm{mg} / \mathrm{kg} \\
\text { DM) }\end{array}$ \\
\hline $\begin{array}{l}\text { November } 2013 \\
(n *=3)\end{array}$ & $\begin{array}{l}4.57 \\
(4.53-4.66)\end{array}$ & $\begin{array}{l}18.33 \\
(11.8-31.2)\end{array}$ & $\begin{array}{l}31.57 \\
(12.54-46.09)\end{array}$ & $\begin{array}{l}216.67 \\
(139.2-258.8)\end{array}$ & $\begin{array}{l}11.23 \\
(6.3-14)\end{array}$ \\
\hline $\begin{array}{l}\text { December } 2013 \\
(n=3)\end{array}$ & $\begin{array}{l}4.8 \\
(4.66-4.92)\end{array}$ & $\begin{array}{l}48.6 \\
(44.4-47.8)\end{array}$ & $\begin{array}{l}8.28 \\
(6.83-9.26)\end{array}$ & $\begin{array}{l}167.67 \\
(35.5-285.6)\end{array}$ & $\begin{array}{l}12.56 \\
(8.6-16)\end{array}$ \\
\hline $\begin{array}{l}\text { January } 2014 \\
(n=7)\end{array}$ & $\begin{array}{l}4.81 \\
(4.63-5.1)\end{array}$ & $\begin{array}{l}44.25 \\
(25.8-55.6)\end{array}$ & $\begin{array}{l}2.03 \\
(1.21-3.4)\end{array}$ & $\begin{array}{l}240.96 \\
(83.6-562.8)\end{array}$ & $\begin{array}{l}12.37 \\
(7.8-15.2)\end{array}$ \\
\hline $\begin{array}{l}\text { February } 2014 \\
(n=3)\end{array}$ & $\begin{array}{l}4.69 \\
(4.53-4.83) \\
\end{array}$ & $\begin{array}{l}60.33 \\
(56.2-64.2)\end{array}$ & $\begin{array}{l}8.25 \\
(6.43-10.01)\end{array}$ & $\begin{array}{l}430.43 \\
(347.3-562.8) \\
\end{array}$ & $\begin{array}{l}10.81 \\
(5.5-14.04)\end{array}$ \\
\hline $\begin{array}{l}\text { Marsh } 2014 \\
(\mathrm{n}=6)\end{array}$ & $\begin{array}{l}4.5 \\
(3.62-4.77) \\
\end{array}$ & $\begin{array}{l}58.57 \\
(46.6-71.6) \\
\end{array}$ & $\begin{array}{l}6.95 \\
(4.08-13.57) \\
\end{array}$ & $\begin{array}{l}496.76 \\
(234.2-646.4) \\
\end{array}$ & $\begin{array}{l}3.22 \\
(1.2-4.3)\end{array}$ \\
\hline $\begin{array}{l}\text { April 2014 } \\
(n=2)\end{array}$ & $\begin{array}{l}4.58 \\
(4.57-4.6)\end{array}$ & $\begin{array}{l}60.0 \\
(54.2-65.8)\end{array}$ & $\begin{array}{l}0.485 \\
(0.44-0.53)\end{array}$ & $\begin{array}{l}9.32 \\
(0.06-18.59\end{array}$ & $\begin{array}{l}0.038 \\
(0.036-0.040)\end{array}$ \\
\hline
\end{tabular}

$\mathrm{n}: \mathrm{Nb}$ of analysed samples

\subsection{Therapeutic trials}

It should be noted that removal of affected animals from their original pasture and their maintenance under controlled feeding conditions resulted in spontaneous recovery of two animals among seven.

The use of thiamine derivative (sulbutiamine) has resulted in clinical recovery of all treated animals. However, recovery delay (> 7 days) in six animals and relapse (after about 2 months) in one ram after oral sulbutiamine have needed the use of the injectable form of sulbutiamine (Table 2).

Table 2 : Therapeutic protocol and results

\begin{tabular}{|l|l|l|l|l|}
\hline Treatment & \multirow{2}{*}{ Nb. animal } & \multicolumn{2}{|l|}{ Sexe } & Clinical recovery (Nb) \\
\cline { 3 - 6 } & & Male & Female & \\
\hline Sulbutiamine oral suspension (10\%) & 39 & 3 & 36 & 32 \\
\hline Sulbutiamine injection (10\%) (i.m.)* & 4 & 0 & 4 & 4 \\
\hline $\begin{array}{l}\text { Recovery delay or relapse after } \\
\text { sulbutiamine oral suspension and use of } \\
\text { injectable solution. }\end{array}$ & 7 & 2 & 5 & 7 \\
\hline
\end{tabular}

*i.m. : intramuscular

\section{Discussion:-}

The present study aimed to determine the potential role of thiamine derivatives in alleviating the clinical manifestations and pathological changes associated with $C$. salviifolius poisoning in sheep. It should be noted first that from biochemical point of view, no poisoning indicative abnormalities were detected in any affected animal. Clinically, poisoned animal were susceptible to convulsions following any external stimuli and, often, bears traces of falls. This symptomatology is in accordance with what had been described in Spain and Portugal (Soler Rodriguez et al., 1995; San Andrés et al., 2000;Soler Rodríguez, 2000).

The observed symptomatology in sheep poisoned by $C$. salviifolius was largely similar to that observed in animals deficient in thiamine, ie convulsions, nystagmus and Opisthotonus. In this context, the use of sulbutiamine at a dosage rate of approximately 30 to $60 \mathrm{mg} / \mathrm{kg}$ BW orally during 4 to 7 days or 5 to $15 \mathrm{mg} / \mathrm{kg} \mathrm{BW}$ as single IM injection allowed recovery of $82 \%$ and $100 \%$ of treated animals respectively. Sulbutiamine injection seems to be more active than oral suspension. Indeed, although it was tested on a limited number of animals, sulbutiamine injection showed a $100 \%$ recovery. Furthermore, the IM injection has enabled the recovery of animals that showed delayed recovery or relapsed after oral preparation. However, therapeutic failures observed with the oral form were largely attributed to insufficient observance of our recommendation by the owners. Moreover, among the seven sheep that had needed further treatment with injectable sulbutiamine, only one case of relapse was observed and concerned a ram who showed a brief seizure during the shearing operation two months later after recovery. 
The thiamine used in this study was in the form of disulfide thiamine derivative and is also used in human being for the treatment of asthenia, memory improvement and the reduction of psycho-behavioral inhibition. The sulbutiamineis a lipophilic compound that crosses the blood-brain barrier more easily than thiamine and increases thiamine phosphate esters levels in the brain (Bettendorff et al., 1990).

C. salviifoliusis a perennial plant whose foliage regenerates and abounds after the early autumn rains. It is of significant nutritional value (Bruno-Soares et al., 2011). However, when eaten as a main feed source or in large amounts, this shrub can cause anti-nutritional and toxic effects (McSweeney et al., 2001). Anti-nutritional effect of rockrose was attributed in part to condensed tannins (CT). In the present study, CT levels of $C$. salviifolius were the highest in samples collected in November, which is in accordance with the results reported by Bruno Soares et al. (2011) in Portugal. The interaction of CT with nutrients usually results in the formation of insoluble and nonabsorbable complexes in the digestive tract (Nuñez-Hernandez et al., 1991). Such effects of tannins had been documented for proteins (McSweeney et al., 2001) and thiamine (Kositawattanakul et al., 1977; Ruenwongsa and Pattanavibag, 1984). In their study, Ruenwongsa and Pattanavibag (1984) have shown that the consumption of a diet rich in tannins, such as tea, generates thiamine deficiency in rats. In ruminants and under normal conditions, thiamine is synthesized by rumen flora in sufficient amounts to cover animal requirements (Bechdel et $a l ., 1928$; Poe et al.; 1974). Thus, by their antimicrobial effect (Scalbert, 1991; Bouamama et al., 2006), tannins can destroy the flora synthesizing thiamine and enhance the deficiency of this vitamin. The interaction of $C$. salviifolius with thiamine could also, at least partly, due to the presence of substances with thiaminase activity in this plant. Theses two hypothesis were in part confirmed in a separate study by the use rumen fluid from healthy goats in two affected sheep that have not completely responded to the administration of thiamine hydrochloride injection. This act allowed the complete recovery of one animal and delayed seizures occurrence (about 3 weeks) in the other (Oukessou, unpublished results).

In addition to tannins, rockrose contains other compounds of obvious toxicological concern namely sulfurs. Indeed, it has been reported that high levels of these compounds in the diet cause Polioencephalomalacia (PEM) in cattle (Haydock, 2003) and sheep (Gooneratne et al., 1989; Olkowski et al., 1992; Olkowski, 1997). The sulfur-induced PEM appears to result from a direct effect of these compounds (Olkowski et al., 1992; Haydock, 2003), but also from their interaction with thiamine (Gooneratne et al., 1989; Olkowski et al., 1992; Amat et al., 2013). This dual action of sulfur might explain the failure of thiamine-based-treatment, or the use of high doses of this vitamin, in certain forms of PEM treatment (Haydock, 2003). An example of PEM described in cattle without any alteration in animals thiamine status, was reported and was attributed to excessive intake of sulfur. This form of PEM was encountered in animals receiving a molasses-urea based diet (Gould, 1998). Furthermore, inactivation of thiamine by sulfur have been well elucidated in cats (Steel, 1997) and dogs (Singh et al., 2005) fed sulfite preserved meat. In the latter study, MRI revealed bilaterally symmetrical hyperintensity of the caudate nucleus and rostral colliculi, which are two vulnerable area to thiamine deficiency. Thiamine deficiency in this study was further supported by thiamine pyrophosphate assay and animal recovery following thiamine supplementation.

In ruminants, the majority of ingested sulfur is reduced to sulfites by rumen microorganisms. Sulfites are then incorporated in the microbial protein synthesis or oxidized to sulfates in the liver. Sulfates are reduced mainly to hydrogen sulfide $\left(\mathrm{H}_{2} \mathrm{~S}\right)$. The production in excess of the latter product followed by its absorption causes several problems including PEM lesions (Gould et al., 1997; McAllister et al., 1997). The rumen $\mathrm{H}_{2} \mathrm{~S}$ concentration is $\mathrm{pH}-$ dependent; it increases with $\mathrm{pH}$ decreasing (McAllister et al., 1997). For example, when the pH of the rumen decreased from 6.8 to 5.2, the proportion of $\mathrm{H}_{2} \mathrm{~S}$ in the rumen gas increased from 46.8 to $97.2 \%$ (Bray and Till, 1975) and development of PEM in cattle can be occurred from rumen $\mathrm{H}_{2} \mathrm{~S}$ levels above 2000 ppm (Gould, 1998).

In addition to increasing the production of $\mathrm{H}_{2} \mathrm{~S}$, chronic rumen acidosis conditions favor the development of thiaminases producing bacteria such as Megasphaeraelsdenii (Alves De Oliveira et al., 1997).

In our study, two major factors would assume that ingested sulfur levels were high during the disease occurrence period. Firstly, rockrose sulfates and sulfites levels were on average the highest from November throughout March, period which corresponds to the onset of the disease, and secondly rumen acidification ( $\mathrm{pH}$ decrease) will increase following rockrose consumption. However, it would be difficult to decide on the fate of sulfur in rumen environment in affected sheep or on the physiological capacity of the animal to buffer the acidifying effects of the rockrose.

It is apparent from the present study that $C$. salviifolius neurotoxicity would be consecutive to the interaction of the components of this shrub (tannins, sulfur...) with the synthesis and/or the metabolism of thiamine. Moreover, our results support that the observed nervous disorder in sheep is initially functional and spontaneously reversible, but 
may progress to organic state with a poor prognosis needing treatment. In fact, among three clinically affected sheep, only one has showed characteristic lesions of thiamine deficiency and it was observed that the withdrawal of animals, at the beginning of the disease onset, from their environment to another without rockrose, was sufficient to induce spontaneous recovery.

From the above-mentioned data, two questions at least arise and remain to be elucidated. These questions concern (i) the relation between the onset of seizures and external stimulus and (ii) the thiamine action mechanism in stopping seizures.

It may therefore be postulated, and simplistically, that rockrose poisoning induced-seizures would be consecutive to central nervous system increased levels of the main excitatory amino-acids namely L-glutamate and Aspartate, following alteration in production and/or synaptic uptake of these neurotransmitters, and/or synthesis reduction or conversion increase of the inhibitory neurotransmitter (GABA). Such aspects were not investigated during the present work. However, based on either reported data relating thiamine and neurotransmission and therapeutic results obtained in our study, the hypothesis of excitotoxicity phenomenon could be evoked to explain seizures induced by cistus poisoning. In fact, thiamine and its esters act as cofactors in a variety of metabolic functions throughout the body. These cofactors, mainly thiamine pyrophosphate (TPP), are required in sufficient amounts for the oxidation of pyruvate and alpha-ketoglutarate, which are essential steps in the Krebs cycle (Gerald and Combs, 2012). Moreover, at nervous function level, thiamine is also involved in the synthesis of neurotransmitters such as acetylcholine, glutamate and GABA (Butterworth, 1982; Plaitakis et al., 1982; Gerald and Combs, 2012). With respect to the relationship between thiamine and glutamate, it is well documented that thiamin deficiency leads to abnormal regulation of glutamatergic pathway (Butterworth, 1982; Plaitakis et al., 1982; Gerald and Combs, 2012). However, the published results on this subject are discordant. Some authors have described a decrease in glutamate levels in the whole brain (Gublerb et al., 1972; Navarro, 2008; Nardone et al., 2013), whereas others have reported that the reduction in the thalamus is moderate for glutamate but very severe for aspartate in deficient thiamine rats (Butterworth et al., 1989). In contrast, another study using micro-dialysis techniques, has shown that the level of glutamate in the extracellular medium of the ventral postero-medial nucleus of thalamus (a vulnerable thiamine deficiency area) become significantly higher in the thiamine deficient group after the onset of symptoms (Todd and Butterworth, 2001). It was also found, in an animal model of Wernicke-Korsakoff syndrome, that thiamine deficiency induced a significant decrease of glutamate uptake in the prefrontal cortex (Carvalho et al., 2006) which may lead to excitotoxicity phenomena and neuronal death.

Glutamate levels at the central level can also be influenced by sulfites. Indeed, besides thiamine inactivation, sulfites exert a neurotoxic effect by inhibiting the enzyme glutamate dehydrogenase (GDH), which results in glutamate accumulation (Zhang et al., 2004). In the present study, the observed level of sulfites and sulfates in $C$. salviifolius may contribute to increase the pool of sulfites in poisoned sheep.

Regarding GABA, it has been reported that chronic thiamine deprivation in rats leads to a significant decrease in the concentration of this inhibitory neurotransmitter in whole brain (Guble et al., 1974 ; see for review Butterworth, 1982).

It is important, however, to note that the observed symptoms in the $C$. salviifolius poisoned animals could not be attributed solely to neurotransmitters actions. Indeed, thiamine deficiency causes a reduction of the pyruvate dehydrogenase complex activity, responsible, together with thiamine pyrophosphate as a cofactor, of pyruvate transformation to acetyl-CoA; resulting in lactate accumulation (lactic acidosis) in various brain areas, including the medial thalamus, considered as a vulnerable region to thiamine deficiency (Navarro, 2008). According to this author, the administration of a glucose load to deficient thiamine rats, exacerbates lactate accumulation in the medial thalamus and could explain the worsening nervous symptoms caused by glucose in patients suffering from Wernicke encephalopathy, a neurological disorder caused by thiamine deficiency in human. This metabolic glucose intolerance described in humans suffering from Wernicke's encephalopathy (Watson et al., 1981) and in the thiamine-deficient rat (Navarro, 2008) was also observed in our study in sheep receiving a cereal (maize or barley) based-ration.

\section{Conclusion:-}

This study constitutes a new therapeutic approach to neurological disorders caused by rockrose poisoning in sheep and supports the hypothesis of thiamine deficiency as a major cause of the observed symptoms. 


\section{Conflict of interest:-}

We would like to confirm that there is no conflict of interest associated with this publication.

\section{Acknowledgments:-}

Thanks are due to Mrs S. Suilahi, A. Louriti and all the sheep farmers in the AitIchou area.

\section{References:-}

1. Alves De Oliveira, L., Jean-Blain, C., Komisarczuk-Bony, S., Durix, L.A., Durier, C. (1997). Microbial thiamine metabolism in the rumen simulating fermenter (RUSITEC): the effect of acidogenic conditions, a high sulfur level and added thiamine. Bri. J. Nutri., 78(4), 599-613.

2. Amat, S., Mckinnon, J.J., Olkowski, A.A., Penner, G.B., Simko, E., Shand, P.J., Hendrick, S. (2013): Understanding the role of sulfur-thiamine interaction in the pathogenesis of sulfur-induced polioencephalomalacia in beef cattle. Res. Vet. Sci., 95, 1081-1087.

3. Bechdel, S. I., Honeywell, H. E., Dutcher, R. A., Knutson, M. H. (1928). Synthesis of vitamin B in the rumen of the cow. J. Biol. Chemist., 80, 231-238.

4. Bettendorff, L., Weeker, Pierre Wins, P., Schoffeniel, E. (1990). Injection of sulbutiamine induces an increase in thiamine tripbosphate in rat tissues. Bioch. Pharmacol., 40(11), 2557-2560.

5. Bouamama, H., Noël, T., Villard, J., Benharref, A., Jana, M. (2006). Antimicrobial activities of the leaf extracts of two Moroccan Cistus L. species. J. Ethnopharmacol., 104,104-107.

6. Bray, A.C., Till, A.R. (1975). Digestion and metabolism in the ruminant. (Eds)

7. I.W.McDonald and A.C.I. Warner, pp.243-260. (University of New England Publishing Unit, Armidale, NSW.

8. Bruno-Soares, A.M., Abreu, J.M., Soler, F. (2004). Preliminary in vitro studies of Cistussalviifolius leaves in relation to metabolic disorders in sheep. In : Poisonous plants and related toxins. T. ACAMOVIC, C.S. STEWART and T.W. PENNECOTT (éd.). CABI Publishing, Wallingford, Oxon OX10 8DE, UK, pp. 55-62.

9. Bruno-Soares, A.M., Matos, T.J.S., Cadima, J. (2011). Nutritive value of Cistussalvifolius shrubs for small ruminants. Ani. Feed. Sci. Technol., 165, 167-175.

10. Butterworth, R.F., Héroux, M. (1989). Effect of Pyrithiamine Treatment and Subsequent Thiamine Rehabilitation on Regional Cerebral Amino Acids and Thiamine-Dependent Enzymes. J. Neurochem., 52, 1079-1084.

11. Butterworth, R.F., (1982). Neurotransmitter function in thiamine-deficiency encephalopathy. Neurochem. Int., 4, 449-46.

12. Carvalho, F.M.., Pereira, S.R.C., Pires, R.G.W.., Ferraz, V.P., Marco Romano-Silva, M.A., Oliveira-Silva, I.F., Ribeiro, A. M. (2006). Thiamine deficiency decreases glutamate uptake in the prefrontal cortex and impairs spatial memory performance in a water maze test. Pharmacol. Biochem. Behav., 83, 481-489.

13. De Vincente, M.L., San Andres Larrea, M.I. , Capo Marti, M.A. (1989). Etude toxicologique des fractions éthérées de Cistusmonspeliensis chez la souris. Rev. Méd. Vét., 140(3), 207-211.

14. Gerald, F., Combs, J.R. (2012). Thiamin. In : The Vitamins. Fundamental aspect in nutrition and health. Elsevier Inc., $4^{\text {th }}$ Edn., pp. 262-275.

15. Gooneratne, S.R., Olkowski, A.A., Christensen, D.A. (1989). Sulfur-induced Polioencephalomalacia in Sheep: Some Biochemical Changes. Can. J. Vet. Res., 53, 462-467

16. Gould, D. H. 1998. Polioencephalomalacia. J. Anim. Sci., 76:309-314.

17. Gould, D.H., Cummings, B.A., Hamar, D W. (1997). In vivo indicators of pathologic ruminal sulfide production in steers with diet-induced polioencephalomalacia. J. Vet. Diagn. Invest., 9(1):72-76.

18. Gublerb, C. J., Adam, B.L., Hammonedn, B., Yuan, E.C., Guo, S.M., Bennion, M. (1974). Effect of thiamine deprivation and thiamine antagonists on the level of $\gamma$-aminobutyric acid and on 2-oxoglutarate metabolism in rat. J. Neurochem.,22, 831-836.

19. Haydock, D. (2003). Sulfur-induced polioencephalomalacia in a herd of rotationally grazed beef cattle. Can. Vet. J., 44, 828-829.

20. Kositawattanakul, T., Tosukhowong, P., Vimokesant, S.L., Panijpan, B. (1977). Chemical interactions between thiamine and tannic acid II.Separation of products. Am.J. Clin. Nutr., 30,1686-1691.

21. Lahkak, F.E., Bencheikh, F.Z., Oukessou, M. (2014). Contribution à l'étude d'un Syndrome nerveux chez les ovins au niveau de la Commune d'Ait Ichou, Oulmès : Partie I : Enquêtes Epidémiologiques. Rev. Mar. Sci. Agr. Vét., 2(2), 70 - 74.

22. Lima, M., Peleteiro, M., Malta, M. (2001). A new syndrome in beef cattle, characterized by cystic paralysis and urinary retention, possibly related to winter browsing of the plant Cistussalviifolius: A report of three herd 
outbreaks in Portugal. $6^{\text {th }}$ International Symposium of Poisonous Plants. $6^{\text {th }}-10^{\text {th }}$ August, 2001, Glasgow, Scotland.

23. Mcallister, M.M., Gould, D.H., Raisbeck, M.F., Cummings, B.A., Loneragan, D.H. (1997). Evaluation of ruminal sulphide concentrations and seasonal outbreaks of polioencephalomalacia in beef cattle on a feedlot. J. Am. Vet. Med. Assoc.,211(10), 1275-1279.

24. Mckenzie, R.A., Carmichael, A.M., Schibrowski, M.L., Duigan, S.A., Gibson, J.A., Taylor, J.D. (2009). Sulfurassociated polioencephalomalacia in cattle grazing plants in the family Brassicaceae. Aust. Vet. J., 87, 27-32.

25. Mcsweeney C.S., Palmer B., Mcneill D.M., Krause D.O. (2001): Microbial interactions with tannins: Nutritional consequences for ruminants. Anim. Feed Sci. Technol., 91, 83-93.

26. Nardone, R., Höller. Y., Storti, M., Christova M., Tezzon, F., Golaszewski, S., EugenTrinka, E., Brigo, F. (2013). Thiamine Deficiency Induced Neurochemical, Neuroanatomical, and Neuropsychological Alterations: A Reappraisal. Scient. World. J. Article ID 309143, 1-8.

27. Navarro, D. (2008). Region-selective effects of thiamine deficiency on cerebral in pyrithiamine-treated rats. A thesis submitted to McGill University in partial fulfilment of the requirements of the degree of Ph.D. Department of Medicine, Division of Experimental Medicine McGill University, Montreal, Quebec, Canada.

28. Nuñez-Hernandez, G., Wallace, J.D., Holechek, J. L., Galyean, M. L., Cardenas, M. (1991). Condensed tannins and nutrient utilization by lambs and goats fed low-quality diets. J Anim. Sci., 69:1167-1177.

29. Olkowski, A.A., Gooneratne, S.R., Rousseaux, C.G., Christensen, D.A. (1992). Role of thiamine status in sulphur induced polioencephalomalacia in sheep. Res. Vet. Sci., 52:78-85

30. Olkowski, A.A. (1997). Neurotoxicity and secondary metabolic problems associated with low to moderate levels of exposure to excess dietary sulphur in ruminants: a review. Vet. Hum. Toxicol., 39, 355-360.

31. Plaitakis, A., Hwang, E.C., Woert, M.H., Szilagyi, P.E., Berl, S. (1982). Effect of thiamine deficiency on brain Neurotransmitter systems. Ann. N. Y. Acad. Sci.,378, 367-381.

32. Poe, S.E., Mitchell, G.E., JR., Ely, D.G. (1972). Rumen development in lambs. III. Microbial B-vitamin synthesis. J. Ani. Sci., 34(5), 826-829.

33. Poter, L.J., Hrstich, L.N., Chan, B.G. (1986). The Conversion of Procyanidins and Prodelphinidins to Cyanidin and Delphinidin. Phytochemistry 25(1), 223-230.

34. Rodier, J. (1996). L'analyse de l'eau naturelle, eaux résiduaires, eau de mer. 1383 pages, $8^{\text {ème }}$ Edition, Dénod, Paris.

35. Ruenwongsa, P., Pattanavibag, S. (1984). Impairment of acetylcholine synthesis in thiamine deficient rats developed by prolonged tea consumption. Life Sci., 34, 365-370.

36. San Andrés, M.I., Ballesteros Morneo, E., JuradoCouto, R. (2000). Toxicología animal originadaporplantas : (flora Silvestre española). Trouw Nutrition edn. Complutense. S.A.

37. Scalbert, A. (1991). Antimicrobial properties of tannin. Phytochemistry 30, 3875-3883.

38. Singh, M., Thompson, M., Sullivan, N., Child, G., 2005. Thiamine deficiency in dogs due to the feeding of sulphite preserved meat. Aust. Vet. J., 83:412-417.

39. Soler Rodriguez, F., Garcia Rubio, L., MiguezSantiyan, M.P., Roncero, Y., Cordero, V. (1995). Estadioclinicopatologico de la intoxicaciónnaturalporjara en ovinos. XX JornadasCientíficas de la SociedadEspañola de Ovinotecnia y Caprinotecnia, 25, 26 Y 27 de septiembre de 1995.

40. Soler Rodríguez, F. (2000). Intoxicacionesvegetalescausadaspor el pastoreo en pequeñosrumiantes. ProducciónOvina y CaprinaXXV:Ponencia 2 XXV JORNADAS CIENTIFICAS Y IV INTERNACIONALES DE LA SOCIEDAD ESPAÑOLA DE OVINOTECNIA Y CAPRINOTECNIA Teruel, 28, 29 Y 30 DE SEPTIEMBRE DEL.

41. Steel, R.J.S. (1997). Thiamine deficiency in a cat associated with the preservation of 'pet meat' with sulphur dioxide. Aust. Vet. J., 75(10), 719-721.

42. Todd, K.G., Butterworth, R.F. (2001). In Vivo Microdialysis in an Animal Model of Neurological Disease: Thiamine Deficiency (Wernicke) Encephalopathy. Methods 23, 55-61.

43. Watson, A. J., Walker, J. F., Tomkin, G. H., Finn, M. M., Keogh, J. A. (1981). Acute Wernickes encephalopathy precipitated by glucose loading. Ir. J. Med. Sci.,150(10), 301-303.

44. Yeruham, I., Orgad, U., Avidar, Y., Perl, S., Liberboim, M., Adler, H., Shlosberg, A. (2002). A urinary retention syndrome in beef cows probably caused by ingestion of Cistussalviifolius. Rev. Méd. Vét., 153(10), 627-632

45. Zhang X., Vincent. A.S., Halliwell, B., Wong, K.P. (2004). Mechanism of Sulfite Neurotoxicity: Direct inhibition of glutamate Dehydrogenase. J. Biol. Chemist. ,279, 43035-43045. 